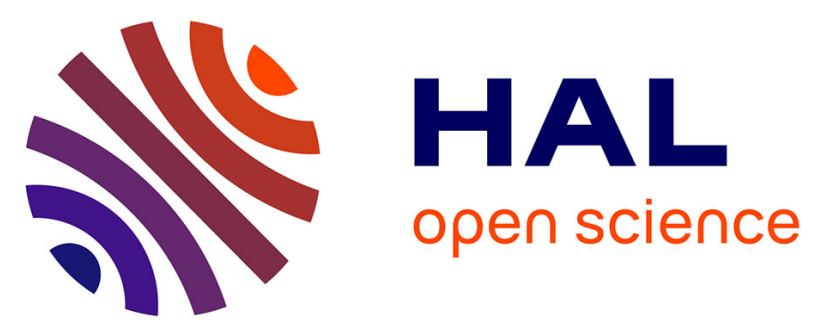

\title{
Anomalous Origin of the Left Coronary Artery From the Pulmonary Artery Presenting in Adulthood: a French Nationwide Retrospective Study
}

Laura Le Berre, Alban-Elouen Baruteau, Alain Fraisse, Dominique Boulmier, Maria Jimenez, Bruno Gallet, Karine Warinfresse, Jacques Mansourati, Patrice Guerin

\section{To cite this version:}

Laura Le Berre, Alban-Elouen Baruteau, Alain Fraisse, Dominique Boulmier, Maria Jimenez, et al.. Anomalous Origin of the Left Coronary Artery From the Pulmonary Artery Presenting in Adulthood: a French Nationwide Retrospective Study. Seminars in Thoracic and Cardiovascular Surgery, 2017, 29 (4), pp.486-490. 10.1053/j.semtcvs.2017.08.018 . hal-01735777

\section{HAL Id: hal-01735777}

https://hal-univ-rennes1.archives-ouvertes.fr/hal-01735777

Submitted on 17 Apr 2018

HAL is a multi-disciplinary open access archive for the deposit and dissemination of scientific research documents, whether they are published or not. The documents may come from teaching and research institutions in France or abroad, or from public or private research centers.
L'archive ouverte pluridisciplinaire HAL, est destinée au dépôt et à la diffusion de documents scientifiques de niveau recherche, publiés ou non, émanant des établissements d'enseignement et de recherche français ou étrangers, des laboratoires publics ou privés. 
3

4

5

6

7

Title: Anomalous origin of the left coronary artery from the pulmonary artery presenting in adulthood: a French nationwide retrospective study.

Authors: Laura Le Berre ${ }^{1}$, MD, Alban-Elouen Baruteau ${ }^{2,3}$, MD, Alain Fraisse ${ }^{4,5}$, MD, PhD, Dominique Boulmier ${ }^{6}, \mathrm{MD}$, Maria Jimenez ${ }^{7}, \mathrm{MD}$, Bruno Gallet ${ }^{8}, \mathrm{MD}, \mathrm{PhD}$, Karine Warin Fresse ${ }^{9}$, MD, Jacques Mansourati ${ }^{1}$, MD, Patrice Guerin ${ }^{9}, \mathrm{MD}, \mathrm{PhD}$.

Affiliations: (1) Brest University Hospital, Western Brittany University, Brest, France (2) MarieLannelongue Hospital, Paris-Sud University, Paris, France (3) Morgan Stanley Children's Hospital, New York Presbyterian, Columbia University Medical Center, New York, NY, USA; (4) AP-HM - La Timone Children Hospital, Marseille, France (5) Royal Brompton Hospital, Harefield NHS Trust, Imperial College London, London, UK (6) Rennes University Hospital, Rennes-1 University, Rennes, France (7) Clinique Saint Augustin, Bordeaux, France (8) Argenteuil Hospital, Argenteuil, France (9) L’Institut du Thorax, Nantes University Hospital, Nantes, France

\section{Date and number of the IRB approval: 24/10/12 Comité de Protection des Personnes Ouest VI}

Address for correspondence: Laura Le Berre - Dherbécourt, Service de Cardiologie Clinique de Keraudren rue Ernestine de Tremaudan, 29200 Brest, France.

Phone: +33 2983490 70, Fax: +33 2983490 71, Email: laura.dherbecourt29@gmail.com

Funding source: none.

Financial disclosure: none

\section{Conflict of interest: none}

Word count: 2876 


\section{Abstract:}

Objective: Anomalous origin of the left coronary artery from the pulmonary artery (ALCAPA) is a rare congenital heart disease usually diagnosed during the first months of life. Without surgical treatment, ALCAPA carries a high mortality risk and disease presentation in adulthood is rare. We describe the diagnosis and management of patients presenting with ALCAPA in adulthood.

Methods: This multicenter French nationwide retrospective study included adult patients diagnosed from 1980 to 2014.

Results: 11 adult patients (mean age: $38 \pm 17$ years) were analyzed. All patients were symptomatic, presenting with chest pain, palpitations, heart failure, and/or syncope. Electrocardiogram was abnormal in $8(73 \%)$ patients. Echocardiogram showed a mildly depressed left ventricular ejection fraction of $50 \pm 13 \%$, kinetic abnormalities in $5(45 \%)$ patients and significant mitral regurgitation in $8(73 \%)$ patients. Coronary angiography was performed in $10(91 \%)$ patients and confirmed the diagnosis. Computerized tomography-scan, magnetic resonance imaging and myocardial scintigraphy were performed when deemed necessary. Ten patients underwent reconstructive surgery but one patient was not operated because of age. Four patients experienced post-operative complications including cardiogenic shock, heart failure, renal failure, and/or additional surgery. After a median follow-up of 2.5 years, all 10 operated patients were alive and asymptomatic and the non-operated patient had died at the age of 70 from syncope related to ventricular tachycardia.

Conclusions: ALCAPA may be diagnosed in adults. Although complications may occur postoperatively, long-term outcome is favorable in adult patients undergoing surgical correction. Surgery should be discussed as first-line therapy in adults with ALCAPA.

(Word count: 250)

Key words: ALCAPA; Bland-White-Garland syndrome; congenital heart disease; myocardial infarction; congenital heart disease 
55

56

57

58

59

60

61

62

63

64

65

66

67

(Character count: 399)

\section{Central Message}

(Character count: 132)

\section{Perspective Statement}

68

ALCAPA is rarely diagnosed in adults but surgical correction in adulthood appears to be associated with favorable long-term outcome.

ALCAPA is a rare congenital heart disease usually diagnosed during the first months of life.

3 Without surgical treatment, mortality is high and presentation in adulthood is rare.

4 We describe the management of 11 adult ALCAPA patients. Although complications may

5 occur post-operatively, long-term outcome is favorable suggesting surgery should be

6 considered as first-line therapy in adults with ALCAPA. 


\section{Abbreviations and Acronyms}

70 ALCAPA = anomalous origin of the left coronary artery from the pulmonary artery

$71 \quad \mathrm{CABG}=$ coronary artery bypass grafting

72 CS = cardiogenic shock

$73 \mathrm{CT}=$ computerized tomography

74 ECG = electrocardiogram

75 HF = heart failure

76 ID $=$ indeterminate

77 LCA = left coronary artery

78 LVEF = left ventricular ejection fraction

79 MRI = magnetic resonance imaging

80 NYHA = New-York Heart Association

$81 \mathrm{P} \quad=$ pericardium patch

$82 \mathrm{R}=$ reimplantation on the ascending aorta

$83 \mathrm{RCA}=$ right coronary artery

$84 \mathrm{RF} \quad=$ renal failure

85 TTE = transthoracic echocardiography 


\section{INTRODUCTION}

In Bland-White-Garland syndrome (also called ALCAPA for anomalous origin of the left coronary artery from the pulmonary artery), the left coronary artery (LCA) arises from the main or left pulmonary artery instead of the aorta. It is a rare congenital heart defect, with an estimated prevalence of 1 case per 300,000 live births (1). In most cases, diagnosis is made in the first year of life but symptom onset usually occurs between 2 and 6 months of age, coinciding with the gradual decline in pulmonary resistance following birth (1). Most often, the coronary artery abnormality is a unique finding and accounts for about 0.25 to $0.5 \%$ of all congenital heart diseases (1). Because perfusion pressure is reduced in the LCA or a steal phenomenon is present between the left and right coronary arteries, ALCAPA is a common cause of myocardial infarction in children and a life-threatening condition if left untreated. Abnormality is more frequent in the LCA but may also involve the right coronary artery $(\mathrm{RCA})(2)$.

During fetal and neonatal periods, ALCAPA is well tolerated as long as pulmonary and systemic pressures are equal (3). After birth, the pulmonary artery pressure decreases and the flow in the LCA reverses resulting in a left-to-right shunt and an abnormal myocardial perfusion leading to myocardial ischemia, mitral regurgitation, left ventricular dysfunction, myocardial infarction, heart failure or sudden cardiac death $(2,4,5)$.

Without proper diagnosis and adequate surgical correction, survival to adulthood is rare and may be attributed to sufficient collateralization between the LCA and RCA. As a consequence, little is known about the course of ALCAPA diagnosed in adulthood and the optimal management of adult patients remains uncertain. We report a nationwide experience with adult patients diagnosed with ALCAPA focusing on disease clinical manifestations, patient management strategies and long-term outcome.

\section{METHODS}

A multicenter retrospective study was carried out at 7 French tertiary hospitals, and consecutive patients over 16 years of age diagnosed with ALCAPA between 1980 and 2014 were included in the analysis.

ALCAPA was defined as an anomalous origin of the left coronary artery that arises from the pulmonary artery instead of the aorta (1). Data were collected from hospital files with special attention given to demographic data, clinical presentation at diagnosis, 12-lead electrocardiogram (ECG), transthoracic echocardiography (TTE), coronary imaging, surgical procedure, post-operative course and clinical status during follow-up. 
Long-term follow-up was assessed by contacting all patients by telephone in 2013 to document the incidence of fatal and non-fatal disease-related adverse events.

The EuroSCORE (European System for Cardiac Operative Risk Evaluation) was assessed for each patient to predict the risk of death after heart surgery. The EuroSCORE is an additive score (6) that takes into account patient-related factors (age, gender, chronic pulmonary disease, extracardiac arteriopathy, neurological disease, previous cardiac surgery, renal impairment, active endocarditis, and critical preoperative state), cardiac-related factors (unstable angina, left ventricular dysfunction, recent myocardial infarct, and pulmonary hypertension) and surgery-related factors (emergency, surgery on thoracic aorta, operation other than isolated coronary artery bypass grafting, and postinfarct septal rupture).

In this non-interventional study, no specific therapeutic protocol was used and the choice of the treatment was made by the treating physician. The study was reviewed and approved by appropriate institutional ethics committees, and all patients granted informed consent to be included into the database.

\section{Statistical analysis}

Relevant variables are expressed as counts and percentages, mean value \pm standard deviation or median with range. Paired t-test was used to compare left ventricular ejection fraction (LVEF) before and after surgery.

\section{RESULTS}

Between 1980 and 2014, 11 adult patients were diagnosed with ALCAPA at the 7 participating centers. Median follow-up was 2.5 years (range: 2.2-24 years).

\section{Patient characteristics}

Most patients were female (64\%) and the diagnosis was made after age 16 at a mean age of $38 \pm 17$ years. Three patients were diagnosed with ALCAPA during routine follow-up for another condition. Among these, 2 had a history of neonatal event: one had unexplained dilated cardiomyopathy that was only explored during adulthood, and the other had a diagnosis of congenital mitral valve regurgitation associated with exostoses and ear aplasia. A third patient presented with dilated cardiomyopathy in adulthood and was subsequently diagnosed with ALCAPA. A case of resuscitated sudden cardiac death due to ventricular fibrillation also led to the diagnosis of ALCAPA. In all 11 patients, only the LCA was abnormal.

All patients were symptomatic at diagnosis, presenting with chest pain (73\%), palpitations (64\%), heart failure (36\%), and/or syncope (9\%) (Table 1). Patients were in New-York Heart Association (NYHA) class II or IV. 
The ECG was abnormal in $8(73 \%)$ patients with $\mathrm{Q}$ waves in lateral leads in one patient, negative $\mathrm{T}$ waves or ST segment in anterior leads in 4 patients. TTE indicated a mean left ventricular diastolic diameter of $58 \pm 9 \mathrm{~mm}$ (from 46 to $71 \mathrm{~mm}$ ) and a mean LVEF of $50 \pm 13 \%$ (from 30 to $69 \%$ ). Left ventricular wall motion was abnormal in 5 (45\%) patients: 2 had akinesia (anterior and apical) and 3 had hypokinesia (septal, anterior, and circumferential). Mitral regurgitation was the only observed valvular disease and was reported in $8(73 \%)$ patients. It was severe (Grade IV) in 2 patients and associated with mitral annulus dilation in 2 patients, mitral valve prolapse in 2 patients, and calcifications in 2 patients. TTE did not allow for the diagnosis of ALCAPA.

Diagnosis was obtained from coronary angiography $(n=10,91 \%)$, computerized tomography $(\mathrm{CT})$ scan $(n=4,36 \%)$, magnetic resonance imaging (MRI, $n=4,36 \%)$, and/or myocardial scintigraphy (exercise myocardial perfusion imaging: $\mathrm{n}=4,36 \%$ ). On average, 2 imaging modalities were necessary per patient to confirm the diagnosis (all 4 tests were necessary in one patient, 2 or 3 in 6 patients and one in 4 patients).

Coronary angiography revealed the presence of giant arteries in the right coronary system, which irrigated the left system, as well as in several collateral arteries. MRI allowed analyzing the myocardial perfusion. Anomalous origin of the left coronary was confirmed and left ventricular function was assessed. Lack of collaterals or their localization was reported (in 2 cases, collaterals were present in the anterior territory). No pericardial abnormality was found. Non-compaction of the left myocardium was found in one patient. Myocardial scintigraphy (exercise myocardial perfusion imaging) was also used to assess myocardial irrigation by collaterals. All patients were found to have perfusion abnormalities, mainly in the antero-septal and antero-lateral territories.

\section{Patient management}

Ten $(91 \%)$ patients underwent surgery (Table 2$)$. The mean Euroscore was $8 \pm 7$. One patient was denied surgery because of age ( 70 years old) and comorbidities. In 6 patients out of 10 operated $(60 \%)$, the left coronary system was reimplanted on the ascending aorta. The other patients underwent closure of the anomalous origin of the coronary artery by a pericardium patch and a single coronary artery bypass grafting (the left anterior descending coronary either by internal mammary artery in 3 patients or saphenous vein in one patient). In one case, the patient had a coronary artery bypass grafting without closure of the LCA. Closure had been performed earlier because of severe pulmonary hypertension to avoid a vascular stealing phenomenon. One patient also underwent mitral valve annuloplasty (another patient had had mitral repair before ALCAPA diagnosis). Extracorporeal circulation lasted $128 \pm 47$ minutes. All operated patients had transthoracic echocardiography; 2 patients had an additional coronary angiography and 2 had myocardial scintigraphy to assess adequate coronary perfusion after surgery. No peri-operative death was reported. Four patients had one or several immediate post-operative complications, which included: cardiogenic shock in 2 patients $(20 \%)$, heart failure in one patient $(10 \%)$, renal failure in 2 patients $(20 \%)$ (requiring hemodialysis in 
one patient), and additional surgery in one patient (10\%). This patient had a stenosis of the LCA and pulmonary truncus requiring subsequent surgical reconstruction and implantation of a stent. This patient also had severe tricuspid regurgitation necessitating close follow-up.

Pharmacological treatment was used in 7 (64\%) patients: angiotensin converting enzyme inhibitors or angiotensin receptor blockers in 3 patients, beta-blockers and loop diuretics in 5 patients each, and anti-platelet agents in 4 patients. One patient received a prophylactic implantable cardiac defibrillator for a low initial LVEF.

\section{Patient long-term follow-up}

Median follow-up was 2.5 years (range: 2.2-24 years). The unoperated patient died at the age of 70: he had syncope related to ventricular tachycardia resulting in cerebral hemorrhage and death. All operated patients were alive at the time of follow-up data collection. No significant LVEF changes were observed (from $50 \pm 13 \%$ to $55 \pm 10 \%(\mathrm{p}=0.15)$ ). NYHA class improved to class I or II for all patients except for the nonoperated patient who remained in class IV. Operated patients with followup (137 99 months) had a sinus rhythm but two cases of paroxysmal arrhythmia were reported (one flutter and one atrial fibrillation). There was no ventricular arrhythmia. Functional tests including coronary angiography, effort test, myocardial scintigraphy, pharmacological stress echocardiography and/or MRI were performed in 7 patients: these assessments were normal with no evidence of coronary disease. Several pregnancies were possible in one female patient.

\section{DISCUSSION}

To the best of our knowledge, this is the largest study on the management and long-term follow-up of adult patients with ALCAPA, a rare congenital abnormality usually diagnosed during childhood. The 11 patients of this study were diagnosed and treated after the age of 16 and had no other medical conditions. They had atypical symptoms and diagnosis was made fortuitously, mainly during assessment of electrocardiographic ischemic signs or mitral regurgitation. Surgery was systematically proposed.

The surgical approach used in the present study consisted in the restoration of a dual coronary artery system, the current technique to repair anomalous origin of coronary arteries $(7,8)$. The procedure is achieved by direct reimplantation of the coronary artery into the aorta by transferring a button of pulmonary artery (a strategy often used in children) (9-12) or by ligature of the origin of the artery along with coronary artery bypass grafting (more frequently used in adults (1)). Surgical strategy can also be influenced by an abnormality of coronary's course, as an intramural course (13). The Takeuchi procedure (14), consisting in a transpulmonary baffle between the coronary ostium in the pulmonary artery and the aorta, is associated with a risk of supravalvular pulmonary stenosis and is more rarely 
used today (7). Cardiac transplantation is reserved for severe left ventricular dysfunction (15). The one-coronary-artery system (coronary artery ligation at its origin) $(14,16,17)$ is no longer performed because of the high risk of complications (severe mitral regurgitation due to ischemic cardiomyopathy or persistent silent ischemia resulting in sudden cardiac death).

In symptomatic patients, the earlier surgery is performed, the better the myocardial recovery. In our study population, the lack of relevant improvement in the mean LVEF (from $50 \pm 13 \%$ before surgery to $55 \pm 10 \%$ after surgery) may be explained by left ventricular dysfunction due myocardial perfusion deficits (chronic ischemia), the presence of arrhythmia or the repair of the mitral valve in some patients. Nevertheless, mitral regurgitation recovered quickly and all operated patients improved their functional status after surgery, even though some of the patients were operated in the 1980's when surgery was not as advanced as it is today.

While coronary angiography remains the reference modality for diagnosis, CT-scan, MRI and myocardial scintigraphy (18-21) are increasingly used to diagnose ALCAPA. These imaging modalities are also useful to noninvasively evaluate the coronary recovery during follow-up, in addition to exercise test or pharmacological stress echocardiography. In particular, MRI may detect chronic myocardial hypoperfusion in an otherwise asymptomatic patient (22).

In our study in adult patients, there were no additional congenital abnormalities associated with ALCAPA, such as atrial or ventricular septum defect or coarctation of the aorta, as can be seen in children (22). This may have contributed to the absence of symptoms until adulthood.

In children, it is expected that in more than half the patients undergoing ALCAPA surgery repair, the severity of mitral regurgitation will spontaneously decrease (23), but no data are available for adult patients. In any case, the benefit of mitral repair has to be compared with the risk of a prolonged bypass time. In our study, mitral regurgitation was present in $73 \%$ patients but only one patient had concomitant mitral valve repair (restrictive annuloplasty). This patient had an initial severe (grade IV) mitral regurgitation with left ventricular dysfunction and pulmonary hypertension.

Overall our study is in line with other reports from the literature $(16,24-27)$ supporting the rarity of ALCAP in adult patients. A comprehensive review of all adult cases in the literature in 2011 by Yau et al. (27) describing 151 ALCAPA patients reported a female preponderance and an average age at presentation in adulthood of 41 years (versus 38 years in our study). In agreement with our observations, patients described in the above reports were likely to have atypical symptoms or present with dysrhythmias, ischemic cardiomyopathy or mitral insufficiency. 


\section{Study limitations}

Our study is limited by the small number of patients included and the high number of patients lost to follow-up but still represent a unique experience given the rarity of data on ALCAPA presenting in adulthood.

In conclusion, ALCAPA rarely presents during adulthood but corrective surgery, which is the gold standard treatment in children, seems to bear excellent long-term prognosis in adult patients, even in patients with atypical symptoms. New noninvasive imaging modalities are now available to evaluate the coronary anatomy and ascertain the diagnosis. Post-operative complications can be managed and surgery permits to correct both the coronary abnormality and the mitral regurgitation thus reducing pharmacologic treatment. Recommendations should be made for the surgical management of patients with ALCAPA. 


\section{Acknowledgments}

We thank the patients for accepting to take part to this study, as well as their general physicians and cardiologists who contributed to data collection. 


\section{$\underline{\text { References }}$}

1. Dodge-Khatami A, Mavroudis C, Backer CL. Anomalous origin of the left coronary artery from the pulmonary artery: collective review of surgical therapy. Ann Thorac Surg. 2002;74(3):94655.

2. Fernandes ED, Kadivar H, Hallman GL, Reul GJ, Ott DA, Cooley DA. Congenital malformations of the coronary arteries: the Texas Heart Institute experience. Ann Thorac Surg. 1992;54(4):732-40.

3. Schwerzmann M, Salehian O, Elliot T, Merchant N, Siu SC, Webb GD. Images in cardiovascular medicine. Anomalous origin of the left coronary artery from the main pulmonary artery in adults: coronary collateralization at its best. Circulation. 2004;110(21):e511-3.

4. Wesselhoeft H, Fawcett JS, Johnson AL. Anomalous origin of the left coronary artery from the pulmonary trunk. Its clinical spectrum, pathology, and pathophysiology, based on a review of 140 cases with seven further cases. Circulation. 1968;38(2):403-25.

5. Arciniegas E, Farooki ZQ, Hakimi M, Green EW. Management of anomalous left coronary artery from the pulmonary artery. Circulation. 1980;62(2 Pt 2):I180-9.

6. Nashef SA, Roques F, Michel P, Gauducheau E, Lemeshow S, Salamon R. European system for cardiac operative risk evaluation (EuroSCORE). Eur J Cardiothorac Surg. 1999;16(1):9-13.

7. Warnes CA, Williams RG, Bashore TM, Child JS, Connolly HM, Dearani JA, et al. ACC/AHA 2008 guidelines for the management of adults with congenital heart disease: a report of the American College of Cardiology/American Heart Association Task Force on Practice Guidelines (Writing Committee to Develop Guidelines on the Management of Adults With Congenital Heart Disease). Developed in Collaboration With the American Society of Echocardiography, Heart Rhythm Society, International Society for Adult Congenital Heart Disease, Society for Cardiovascular Angiography and Interventions, and Society of Thoracic Surgeons. J Am Coll Cardiol. 2008;52(23):e143-263.

8. Rajbanshi BG, Harold MB, Schaff HV, Daly RC, Phillips SD, Dearani JA. Surgical strategies for anomalous origin of coronary artery from pulmonary artery in adults. J Thorac Cardiovasc Surg. 2014;148(1):220-4.

9. Neches WH, Mathews RA, Park SC, Lenox CC, Zuberbuhler JR, Siewers RD, et al. Anomalous origin of the left coronary artery from the pulmonary artery. A new method of surgical repair. Circulation. 1974;50(3):582-7. 
10. Backer CL, Hillman N, Dodge-Khatami A, Mavroudis C. Anomalous origin of the left coronary artery from the pulmonary artery: Successful surgical strategy without assist devices. Semin Thorac Cardiovasc Surg Pediatr Card Surg Annu. 2000;3:165-72.

11. Bunton R, Jonas RA, Lang P, Rein AJ, Castaneda AR. Anomalous origin of left coronary artery from pulmonary artery. Ligation versus establishment of a two coronary artery system. J Thorac Cardiovasc Surg. 1987;93(1):103-8.

12. Duan X, Yu T, Wang F, Liu H, Sun J, Zhai R. Anomalous origin of the left coronary artery from the pulmonary artery in infants: Imaging findings and clinical implications of cardiac computed tomography. J Comput Assist Tomogr. 2015;39(2):189-95.

13. Zhang H, Cheng P, Jin G, Han D, Luo Y, Li J. Surgical strategies for anomalous origin of the left coronary artery from the right pulmonary artery with an intramural aortic course: A report of 10 cases. J Thorac Cardiovasc Surg. . 2017;153(3):648-53.

14. Takeuchi S, Imamura H, Katsumoto K, Hayashi I, Katohgi T, Yozu R, et al. New surgical method for repair of anomalous left coronary artery from pulmonary artery. J Thorac Cardiovasc Surg. $1979 ; 78(1): 7-11$.

15. Nair KK, Zisman LS, Lader E, Dimova A, Canver CC. Heart transplant for anomalous origin of left coronary artery from pulmonary artery. Ann Thorac Surg. 2003;75(1):282-4; discussion 4-5.

16. Pena E, Nguyen ET, Merchant N, Dennie C. ALCAPA syndrome: not just a pediatric disease. Radiographics. 2009;29(2):553-65.

17. Jin Z, Berger F, Uhlemann F, Schroder C, Hetzer R, Alexi-Meskhishvili V, et al. Improvement in left ventricular dysfunction after aortic reimplantation in 11 consecutive paediatric patients with anomalous origin of the left coronary artery from the pulmonary artery. Early results of a serial echocardiographic follow-up. Eur Heart J. 1994;15(8):1044-9.

18. Tatsuishi W, Machida H, Kodera K, Asano R, Kataoka G, Kubota S, et al. Bland-WhiteGarland syndrome in an elderly woman. J Am Coll Cardiol. 2011;57(22):e373.

19. Bagur R, Michaud N, Bergeron S, Rouleau JR, Rodes-Cabau J, Bertrand OF, et al. Adult Bland-White-Garland syndrome presenting as cardiomyopathy characterized by subendocardial fibrosis. J Am Coll Cardiol. 2010;56(8):e15.

20. Safaa AM, Du LL, Batra R, Essack N. A rare case of adult type ALCAPA syndrome: presentation, diagnosis and management. Heart Lung Circ. 2013;22(6):444-6. 
21. Ripley DP, Gosling OE, Harries S, Spurrell PA, Bellenger NG. Multimodality imaging in bland-White-Garland syndrome in an adult with a left dominant coronary artery system. Congenit Heart Dis. 2014;9(4):E110-2.

22. Quah JX, Hofmeyr L, Haqqani H, Clarke A, Rahman A, Pohlner P, et al. The management of the older adult patient with anomalous left coronary artery from the pulmonary artery syndrome: a presentation of two cases and review of the literature. Congenit Heart Dis. 2014;9(6):E185-94.

23. Ben Ali W, Metton O, Roubertie F, Pouard P, Sidi D, Raisky O, et al. Anomalous origin of the left coronary artery from the pulmonary artery: late results with special attention to the mitral valve. Eur J Cardiothorac Surg. 2009;36(2):244-8; discussion 8-9.

24. Zheng JY, Han L, Ding WH, Jin M, Zhang GZ, Xiao YY, et al. Clinical features and longterm prognosis of patients with anomalous origin of the left coronary artery from the pulmonary artery. Chin Med J (Engl). 2010;123(20):2888-94.

25. Schwartz ML, Jonas RA, Colan SD. Anomalous origin of left coronary artery from pulmonary artery: recovery of left ventricular function after dual coronary repair. J Am Coll Cardiol. 1997;30(2):547-53.

26. Lambert V, Touchot A, Losay J, Piot JD, Henglein D, Serraf A, et al. Midterm results after surgical repair of the anomalous origin of the coronary artery. Circulation. 1996;94(9 Suppl):II38-43.

27. Yau JM, Singh R, Halpern EJ, Fischman D. Anomalous origin of the left coronary artery from the pulmonary artery in adults: a comprehensive review of 151 adult cases and a new diagnosis in a 53-year-old woman. Clin Cardiol. 2011;34(4):204-10. 
Table 1: Patients characteristics at diagnosis

\begin{tabular}{|c|c|c|c|c|c|}
\hline Patient & Gender & $\begin{array}{l}\text { Age at } \\
\text { diagnosis } \\
\text { (years) }\end{array}$ & Symptoms & $\begin{array}{c}\text { NYHA } \\
\text { class }\end{array}$ & $\begin{array}{c}\text { LVEF } \\
(\%)\end{array}$ \\
\hline 1 & $\mathrm{~F}$ & 67 & Chest pain / Palpitations (AF) / HF & ID & 33 \\
\hline 2 & $\mathrm{~F}$ & 47 & Palpitations (VT) & II & 44 \\
\hline 3 & $\mathrm{~F}$ & 41 & Palpitations (VF) & II & 40 \\
\hline 4 & M & 33 & Chest pain & II & 62 \\
\hline 5 & M & 70 & $\begin{array}{c}\text { Chest pain / Palpitations (Al } \\
\text { / HF / syncope }\end{array}$ & IV & 30 \\
\hline 6 & M & 36 & Chest pain Palpitations (AF) & II & 60 \\
\hline 7 & M & 25 & $\mathrm{HF}$ & IV & 42 \\
\hline 8 & $\mathrm{~F}$ & 27 & Chest pain & ID & 60 \\
\hline 9 & M & 16 & Chest pain / Palpitations (JT) & IV & 69 \\
\hline 10 & $\mathrm{~F}$ & 25 & Chest pain & II & 55 \\
\hline 11 & $\mathrm{~F}$ & 31 & Chest pain / Palpitations (AF) & II & 57 \\
\hline All patients & $F: 64 \%$ & & $\begin{array}{c}\text { Palpitations: } 64 \% \\
\text { Heart failure: } 36 \% \\
\text { Syncope: } 9 \%\end{array}$ & $\begin{array}{c}\text { II: } 55 \% \\
\text { III-IV: } 27 \% \\
\text { (ID: } 18 \% \text { ) }\end{array}$ & $50 \pm 13$ \\
\hline
\end{tabular}

Values for all patients are expressed as mean \pm standard deviation or percentage

$\mathrm{F}:$ Female/ M : Male/ AF : atrial fibrillation/ HF : heart failure/ ID : indeterminate / JT : Junctional tachycardia/ LVEF : left ventricular ejection fraction/ NYHA : New-York Heart Association/ VF : ventricular fibrillation/ VT : ventricular tachycardia 
Table 2: Patients characteristics after surgery

\begin{tabular}{|c|c|c|c|c|c|c|c|}
\hline Patient & $\begin{array}{c}\text { Time from } \\
\text { diagnosis } \\
\text { to surgery } \\
\text { (days) }\end{array}$ & $\begin{array}{c}\text { Euro } \\
\text { SCORE }\end{array}$ & $\begin{array}{l}\text { Surgery } \\
\text { procedure }\end{array}$ & $\begin{array}{l}\text { Complications } \\
\text { of surgery }\end{array}$ & $\begin{array}{c}\text { NYHA } \\
\text { class at } \\
\text { last visit }\end{array}$ & $\begin{array}{c}\text { LVEF } \\
\text { at last } \\
\text { visit }\end{array}$ & $\begin{array}{c}\text { Follow- } \\
\text { up } \\
\text { period } \\
\text { (months) }\end{array}$ \\
\hline 1 & 18 & 8 & $\mathrm{P}+\mathrm{CABG}$ & $\begin{array}{c}\mathrm{CS}+\mathrm{HF}+\mathrm{RF}+ \\
\text { dialysis }\end{array}$ & II & 50 & 126 \\
\hline 2 & 44 & 20 & $\mathrm{R}$ & RF & II & 61 & 168 \\
\hline 3 & 14 & 20 & $\mathrm{P}+\mathrm{CABG}$ & $\mathrm{CS}+\mathrm{RF}$ & II & 60 & 72 \\
\hline 4 & 180 & 5 & $\mathrm{R}$ & $\mathrm{O}$ & I & 55 & 30 \\
\hline 5 & & & surgery & & IV & 38 & 18 \\
\hline 6 & ID & 4.6 & $\begin{array}{c}\mathrm{P}+\mathrm{CABG} \\
(\mathrm{V})\end{array}$ & $\mathrm{O}$ & I & 50 & NA \\
\hline 7 & 395 & 1 & CABG & $\mathrm{O}$ & UI & 45 & 288 \\
\hline 8 & ID & 6 & $\mathrm{R}$ & $\begin{array}{l}\text { Additional } \\
\text { surgery* }\end{array}$ & & 60 & NA \\
\hline 9 & ID & 6 & $\mathrm{R}$ & $\mathrm{O}$ & I & 76 & 13 \\
\hline 10 & 32 & 3 & $\mathrm{R}$ & & I & 55 & 2 \\
\hline 11 & 2 & 6 & $\mathrm{R}$ & 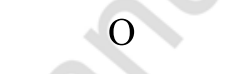 & I & 54 & 11 \\
\hline All patients & 32 [2:395] & $8 \pm 7$ & & & $\begin{array}{l}\text { I-II: 91\% } \\
\text { III-IV: 9\% }\end{array}$ & $55 \pm 10$ & $\begin{array}{c}2.5 \text { years } \\
{[2.2: 24]}\end{array}$ \\
\hline
\end{tabular}

Values for all patients are expressed as median with range or mean \pm standard deviation or percentage

*Patient required additional surgery for left coronary artery and pulmonary artery troncus stenosis with tricuspid regurgitation

CS : cardiogenic shock / CABG : coronary artery bypass grafting / HF : heart failure / NA: Not available / P : Pericardium patch / R : reimplantation on the ascending aorta / RF : Renal Failure / V: venous 


\section{$\underline{\text { Legends }}$}

Central Picture: CT-scan showing abnormal origin of the left coronary artery from the pulmonary artery (white arrow)

Video: Presentation of the article "Anomalous origin of the coronary artery from the pulmonary artery presenting in adulthood: a French nationwide retrospective study" by Professor Patrice Guerin 


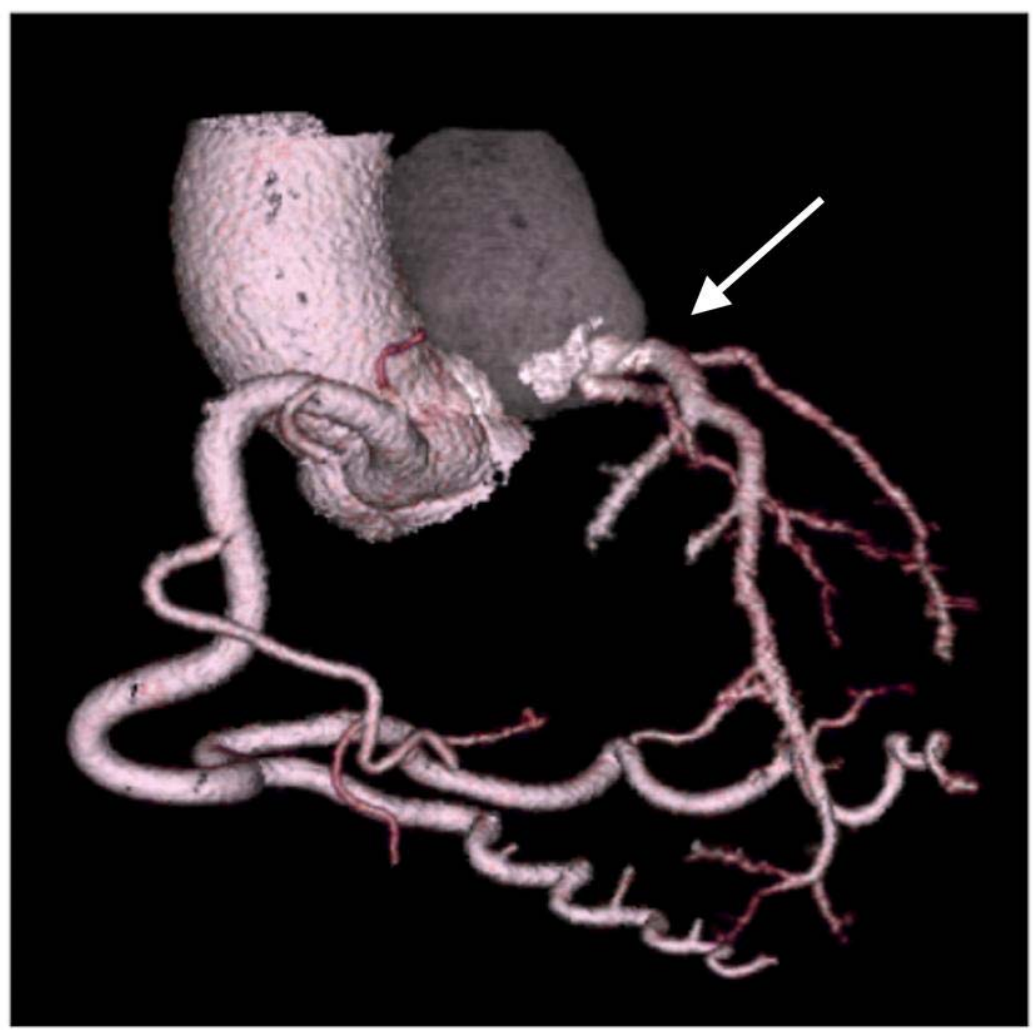

R1 Central picture 2R1.tiff 